\title{
Progressive Spermatozoa Measurement
}

National Cancer Institute

\section{Source}

National Cancer Institute. Progressive Spermatozoa Measurement. NCI Thesaurus.

Code C161366.

The determination of the amount of progressive spermatozoa present in a sample. 